ISSN 0103-5150

Fisioter. Mov., Curitiba, v. 27, n. 4, p. 643-651, out./dez. 2014

Licenciado sob uma Licença Creative Commons

DOI: http://dx.doi.org.10.1590/0103-5150.027.004.A016

\title{
Impact of physical therapy on functional capacity and life quality of patients with chronic kidney disease
}

\author{
Impacto da fisioterapia na qualidade de vida e capacidade \\ funcional em pacientes com doença renal crônica
}

\author{
Georgia Miranda Tomich $^{[a]}$, Luciana Souza Bernardino ${ }^{[b]}$, Fabiana Oliveira Ferreira ${ }^{[c]}$ \\ [a] MSc, Hospital Regional Público do Araguaia, Redenção, PA - Brazil, e-mail: georgiatomich@hotmail.com \\ [b] Spec., Hospital Regional Público do Araguaia, Redenção, PA - Brazil, e-mail: luciana.bernardino@hotmail.com \\ [c] Spec., Hospital Regional Público do Araguaia, Redenção, PA - Brazil, e-mail: fofer24@yahoo.com.br
}

\begin{abstract}
Introduction: Studies have demonstrated beneficial effects of exercise in patients with chronic kidney disease, however, based on current scientific literature, more research is needed to increase evidence level of potential effects of physical activity for this population. Objective: To evaluate effects of physical therapy based on the supervised exercise practice on functional capacity and life quality of patients with chronic kidney disease. Material and methods: This quasi-experimental study, with repeated measures design, was conducted in the ambulatory of physical therapy, in a public hospital, located in a city of the state of Pará (north region of Brazil). Functional capacity and life quality were assessed at baseline and after six weeks of aerobic and resistance training performed three times per week on alternate days with hemodialysis. Results: Eight patients (3M / 5F) with a mean age of 60.38 years (SD $=14.75)$ were evaluated. There was significant increase of $24 \%$ in distance walked in six minute walk test ( $p=0.007$ ), and of $47 \%$ in number of repetitions during sit-to-stand test $(\mathrm{p}=0.002)$; there was also significant improvement in emotional role ( $p=0.043$ ) of life quality assessed with SF36 questionnaire. Conclusion: There was a positive impact of only six weeks of rehabilitation with physical exercise on functional capacity and emotional role of life quality of patients with chronic kidney disease.
\end{abstract}

Keywords: Physical Therapy. Exercise. Rehabilitation. Renal insufficiency. Quality of life. 


\section{Resumo}

Introdução: Estudos têm demonstrado efeitos benéficos do exercício em pacientes com doença renal crônica, no entanto, com base na literatura científica atual, mais pesquisas são necessárias para aumentar o nível de evidência dos efeitos potenciais de atividade física para esta população. Objetivo: Avaliar os efeitos da fisioterapia baseada na prática de exercício supervisionado sobre a capacidade funcional e a qualidade de vida de pacientes com doença renal crônica. Material e métodos: Este estudo quase-experimental, com repetidas medidas projeto, foi realizado no ambulatório de fisioterapia, em um hospital público, localizado em uma cidade do estado do Pará (região norte do Brasil). A capacidade funcional e qualidade de vida foram avaliadas no início e após seis semanas de treinamento aeróbico e de resistência realizados três vezes por semana em dias alternados com hemodiálise. Resultados: Oito pacientes ( $3 M$ / 5F), com idade média de 60,38 anos (DP = 14,75) foram avaliados. Houve aumento significativo de $24 \%$ da distância percorrida no teste de caminhada de seis minutos ( $p=0,007)$, e de 47\% no número de repetições durante o teste sit-to-stand ( $p=0,002)$; também houve melhora significativa nos aspectos emocionais $(p=0,043)$ da qualidade de vida avaliada com questionário SF-36. Conclusão: Houve um impacto positivo de apenas seis semanas de reabilitação com exercício físico na capacidade funcional e aspectos emocionais da qualidade de vida de pacientes com doença renal crônica.

Palavras-chave: Fisioterapia. Exercício. Reabilitação. Insuficiência renal. Qualidade de vida.

\section{Introduction}

Chronic renal insufficiency, renal injury combined with progressive and irreversible loss of kidney function, is nowadays an important medical and public health problem as it is associated with high morbidity and mortality, leading often to disability and appreciable reduction in life quality (1). Following the worldwide trend, there is a growing number of patients on dialysis program in Brazil $(2,3)$.

Among changes resulting from chronic kidney failure, muscle dysfunctions occur. Studies demonstrated presence of atrophy of muscle fibers resulting from an imbalance between synthesis and degradation of muscle protein. There may be decreased synthesis and/or increased degradation $(4,5,6)$. Various mechanisms lead to muscular dysfunction, among which: amino acid depletion; chronic inflammation; inactivity; malnutrition syndrome; change in capillary perfusion; peripheral neuropathy (7).

Literature reports exercise intolerance associated anemia and hypervolemia in patients with chronic renal failure; studies have already showed treatment of these conditions, however, did not improve exercise tolerance, and so, this intolerance consequently leads to a sedentary lifestyle, which decreases even more physical capacity, creating a vicious cycle (7). Bohlke et al. (8) and Hopman et al. (9) observed physical component is more adversely affected by chronic disease in relation to mental component.

Treatment of patients with progressive renal insufficiency can be divided into several components (10), among which health promotion program and primary prevention (based on risk groups), early planning of renal replacement therapy and institution of interventions to slow progression of chronic kidney disease and increase life quality of patients. Physical therapy is included in this component of treatment, based primarily on specific programs of supervised physical exercise, with objective of increasing level of physical fitness and, consequently, improving life quality and decreasing need for antihypertensive medications, morbidity and mortality.

A growing number of scientific studies have identified benefits of physical activity for patients with chronic renal failure $(6,7,11,12,13,14,15,16)$ including: increase of exercise tolerance; reduction of inflammatory mediators; increase of synthesis and decrease in muscle protein degradation; increase of number and size of muscle fibers, thus increasing muscle strength; increase of hematocrit and hemoglobin. Central effects also occur: improve of left ventricular function, decrease in occurrence of cardiac arrhythmias, besides beneficial effects on risk factors for coronary artery disease (hypertension, lipid disorder). 
Studies have been showed beneficial effects of physical exercises on patients with chronic kidney disease. However, in northern region in Brazil, where the present study was conducted, studies are rare, and reflecting misinformation and political aspects, benefits of structured programs are still not available to majority of patients. According to current scientific literature, further studies can contribute to base implementation of policies in public and private health care system, making this method available to all patients who meet indications criteria.

This study aimed to evaluate effects of physical therapy, based on practice of supervised physical exercises, on functional capacity and life quality of chronic kidney disease patients.

\section{Material and methods}

This quasi-experimental study, with repeated measures design, was held in the ambulatory of physical therapy, in a public hospital, which serves 15 cities in the Southeast of the state of Pará (northern Brazil) and has structure of hemodialysis, outpatient, wards and intensive care units.

For inclusion in study, patient should have age over 18 years, make part of the hospital's hemodialysis program, receive medical prescription for practice of physical activity, and sign an informed consent. This study was carried out in accordance with National Health Council Resolution No. 196/96 of the Brazilian Ministry of Health, and approved by the Research Ethics Committee of the Tropical Medicine Foundation of Tocantins (protocol No. 023/2011).

Contraindications to physical activity practice were considered exclusion criteria: recent myocardial infarction; uncontrolled arrhythmias; uncontrolled hypertension (systolic blood pressure > $200 \mathrm{mmHg}$ and diastolic blood pressure $>120 \mathrm{mmHg}$ ); unstable angina; severe decompensate diabetes (blood glucose $>300 \mathrm{mg} / \mathrm{dL}$ ); left ventricle dysfunction; presence of neurological or motor dysfunction impeditive for implementation of protocol of physical activity. Other exclusion criteria were: tumor; pregnancy; stopping treatment during first 6 weeks for more than 3 consecutive sessions.

At beginning of each exercise session, if patient had any symptoms that prevented exercises performance, it was canceled. After beginning of session, break criteria were considered: account of intense physical tiredness, chest pain, dizziness, paleness, syncope, pre-syncope, dyspnea disproportionate to effort intensity, arrhythmia and hypotension or hypertensive response. When any of these symptoms was detected, patient was transferred to hemodialysis service for medical evaluation.

Initially, an interview was conducted with patient, to collect data as previous and current history, co-morbidities, medications, postural changes, vital signs. In initial contact and after six weeks, in addition to anthropometric data, following evaluations were carried out in order to assess effects of exercise protocol:

- Six-minute walk test (6MWT): measurement of functional capacity, which was carried out following the recommendations from the American Thoracic Society (17). This test has already been used in patients with chronic kidney disease in different studies found in literature; Reboredo et al. (18) found a strong correlation between distance obtained in 6MWT and peak oxygen consumption, suggesting this test as a simple and inexpensive alternative for assessing functional capacity of patients with chronic kidney disease who are undergoing hemodialysis treatment.

- Sit-to-stand test: test initially described as a measure of strength of lower extremity, it is currently also considered a balancing test and has already been validated in patients with chronic kidney disease (4).

- Life quality assessment: generic questionnaire Short-form 36 (SF36), translated into Portuguese was used. Johansen et al. (19) considered physical component of SF36 valid to assess physical performance in patients with chronic kidney disease on hemodialysis. Other authors such as Bohlke et al. (8) and Arenas et al. (20) used this test in patients with chronic kidney disease.

In all sessions, following measurements were performed: body weight and blood pressure, heart rate and peripheral oxygen saturation in the pre, during and post session. The exercises were: heating and stretching during 5 minutes, followed by aerobic physical exercise on treadmill and/or bike (about 30 minutes), muscle strengthening exercises (15 to 20 minutes), cooling and stretching (5 minutes). The time 
for aerobic and strengthening varied according to the tolerance of the patient. The resistance exercises were conducted for major muscle groups of lower limbs. All these activities were performed under supervision and guidance of a physiotherapist responsible for research: total duration of session was about 60 minutes 5 minutes for daily assessment of patient, and remaining 55 minutes divided among exercises.

Program of resistance and aerobic training was initiated at low intensity and with a slow progressing according to patient's tolerance (21). In aerobic exercise, for greater effectiveness of training, literature recommends moderate intensity, which corresponds with 50 to $70 \%$ of maximum heart rate and score of Borg scale around 13. These were criteria considered in this study. Patients were instructed to keep speed most constant as possible during exercise on treadmill or cycle ergometer. For muscle strengthening exercises, number of repetitions varied from 1 to 4 sets of 10 to 15 repetitions.

Exercises were held three times a week on alternate days to hemodialysis sessions. According to literature, it is recommend at least three weekly sessions of 45 to 90 minute supervised exercises (22).

Equipment for carrying out exercises and evaluations were blood pressure device, stethoscope, pulse oximeter, treadmill, cycle ergometry, mats, pillows, lingbar, dumbbells, elastic bands (Theraband ${ }^{\circledR}$ ), shin pads, therapeutic balls, chairs, two steps stairs.

Data were analyzed with Statistical Package for the Social Sciences (SPSS) version 20.0 for Windows and are expressed as mean \pm standard deviation. Shapiro-Wilk test was applied to verify data normality. For comparison of averages obtained at beginning and in reevaluation after six weeks paired $t$ test or Wilcoxon test was used, depending on data distribution. In all analyses, a statistical significance level of 0.05 was considered. Effect size was calculated for comparisons performed with paired $t$ test when significant difference was detected (23).

Data collection was performed by only one physiotherapist. After the end of data collection period, patients remained in rehabilitation service to continue practice of physical activity.

\section{Results}

At beginning of this study, 59 patients were indicated to rehabilitation program; it was possible to schedule initial interview with 44 patients, among whom 26 attended this initial interview, 18 attended baseline tests and first session, and eight remained until reevaluation after six weeks. When data were collected, this sample of eight patients represented $10 \%$ of those assisted in hemodialysis department. Among 10 patients who initially joined program and did not complete six weeks of treatment, justifications presented for dropping out treatment were: depression $(n=3)$, difficulty of transport $(n=2)$, family problems $(n=1)$, labyrinthitis $(n=1)$, lack of time $(\mathrm{n}=1)$, pain and difficulty of locomotion $(n=1)$, hospitalization for surgery $(n=1)$.

Among eight patients included that remained after six weeks, average age was $60.38 \pm 14.75$ years, being 3 men (37.5\%) and 5 women (62.5\%). Most frequent etiology of chronic kidney disease was hypertension: five patients $(62.5 \%)$ were hypertensive and were under medical treatment.

There was a positive impact of six weeks of rehabilitation with physical exercise on functional capacity of patients. Table 1 shows results of evaluations performed with 6MWT and sit-to-stand test.

After six weeks of rehabilitation, distance walked in 6MWT increased by $24 \%$ with statistical significance $(p=0.007)$, indicating important improve in functional capacity with a moderate effect size of 0.46 . Parallel to increase in distance walked, there was a significant increase of almost $50 \%$ in number of repetitions patients reached in sit-to-stand test $(p=0.002)$, which indicates improvement in strength and in balance of lower limbs, and also in functional capacity, with a large effect size of 0.80 .

Table 2 shows means of life quality scores obtained in initial evaluation and after six weeks of training. There was a positive and significant impact of rehabilitation program in emotional role score.

\section{Discussion}

Several types of tests can be used to assess functional capacity in general population and in patients with chronic renal disease. Between these tests, 6MWT stands out, being one of most widely used tests in literature, because it is validated, of low cost and easily applied (24). In this study, 6 MWT was used with no difficulties. 
Table 1 - Functional capacity scores obtained at baseline and after six weeks of rehabilitation based on physical exercises in eight patients with chronic kidney disease

\begin{tabular}{lccc}
\hline Functional capacity score & Baseline & After six weeks & p value \\
\hline Distance in 6MWT $(\mathrm{m})$ & $290 \pm 164$ & $361 \pm 145$ & $0.007^{*}$ \\
Repetitions in sit-to-stand test $(\mathrm{n})$ & $9 \pm 5$ & $13 \pm 5$ & $0.002^{*}$ \\
\hline
\end{tabular}

Note: Results are expressed as mean $\pm \mathrm{SD}$. Comparisons performed using paired $t$ test. ${ }^{*} p<0.05$ considered statistically significant

Table 2 - Quality of life scores obtained at baseline and after six weeks of rehabilitation based on physical exercises in eight patients with chronic kidney disease

\begin{tabular}{cccc}
\hline SF36 dimensions & Baseline & After six weeks & p value \\
\hline Physical functioning & $40 \pm 37$ & $53 \pm 27$ & $0.059 \dagger$ \\
Physical role & $44 \pm 26$ & $53 \pm 36$ & $0.476 \dagger$ \\
Bodily pain & $61 \pm 30$ & $64 \pm 27$ & $0.499 \dagger$ \\
General health & $47 \pm 36$ & $61 \pm 24$ & $0.256 \dagger$ \\
Vitality & $53 \pm 14$ & $66 \pm 7$ & $0.072 \dagger$ \\
Social functioning & $70 \pm 22$ & $63 \pm 27$ & $0.726 \S$ \\
Emotional role & $13 \pm 18$ & $50 \pm 40$ & $0.043 \S^{*}$ \\
Mental health & $67 \pm 19$ & $68 \pm 27$ & $0.932 \dagger$ \\
\hline
\end{tabular}

Note: Results are expressed as mean $\pm \mathrm{SD}$. † Comparisons performed using paired $\mathrm{t}$ test. $\S$ Comparisons performed using Wilcoxon test. ${ }^{*} p<0.05$ considered statistically significant

Hemodialysis patients have considerable reduction of functional capacity in relation to sedentary healthy individuals of similar sex and age $(25,26$, 27). In the present study, average distance walked by patients in 6 MWT was $290 \mathrm{~m} \mathrm{(} \pm 164 \mathrm{~m}$ ) in initial assessment, under values found by Dipp et al. (27) (397 $\pm 104 \mathrm{~m})$, Jatobá et al. (25) (493 $\pm 147 \mathrm{~m})$, Reboredo et al. (18) (516 $\pm 89 \mathrm{~m}$ ), Painter et al. (28) (517 $\pm 189 \mathrm{~m})$, Parsons et al. (29) (101 $\pm 520 \mathrm{~m})$, Headley et al. (30) (522 $\pm 46 \mathrm{~m})$, in chronic renal patients undergoing dialysis. A possible explanation for this difference may be related to greater average age of population of this study in relation to other cited. Baseline result obtained in 6MWT reflected substantial physical limitation, which is consistent with patients' interview, because all of them testified they were sedentary and with important limitations in daily life.
There was a increase in distance walked in 6MWT after six weeks of rehabilitation, and it was above result found by Parsons et al. (29), who observed increase of $14 \%$ in $6 \mathrm{MWT}$ after 20 weeks of training in 13 hemodialysis patients, and observed by Henrique et al. (31), who found an increase of $9 \%$ in distance walked in 6MWT after three months of aerobic exercise performed during hemodialysis sessions.

Considering number of repetitions patients reached in sit-to-stand test, there was a significant increase of almost $50 \%$. Kouidi et al. (32) evaluated seven patients by dynamometry and muscle biopsy with histological, microscopic and histochemistry analyses, before and after general fitness training and muscle strengthening during interdialytic period; results showed training improved $42 \%$ muscle strength of lower limbs and decreased number of atrophic fibers and significant increases in cross-cutting areas 
in muscle fibers, especially in type II, which reflected in increased $48 \%$ in $\mathrm{VO}_{2}$ (peak) and $29 \%$ in exercise time.

Combination of aerobic and strength training of lower limbs can be one of explanations for significant gains in functional capacity, who suffers influence of peripheral factors such as muscle atrophy and weakness, besides cardiorrespiratory conditioning (32). In study of Headley et al. (30) there was a significant increase in distance measured with 6MWT after 12 weeks of strength training in 10 patients with chronic kidney disease on hemodialysis, what is suggestive that impairment of functional capacity may be mitigated by gain of muscle strength.

Several authors have demonstrated chronic kidney disease and dialysis treatment generate negative impacts on life quality of these patients $(33,34,35,36)$. According to Silveira et al. (37), health-related life quality of hemodialysis patients evaluated in a public hospital in city of Belem (PA - Brazil) was globally reduced in all age groups, especially with regard to physical aspects, similar to result found by Martins and Cesarino (11). In addition to these aspects, losses in quality of life are associated with problems such as social isolation, loss of job, loss of authority in family context, partial impossibility of locomotion due to overall clinical status, impossibility of prolonged trips due to hemodialysis sessions frequency, sexual dysfunction, food restriction, among others (38).

With rehabilitation program, in addition to impact on functional capacity, it is expected changes in life quality. Scores obtained initially with SF36 in this study were generally lower than those obtained for Silveira et al. (37), who evaluated 50 dialysis patients, with a mean age of 48 years, as also by Bohlke et al. (8), which assessed 140 dialysis patients, with an average age of 54 years. In both studies, authors found that older age, among other factors, negatively influence life quality; age, therefore, may have contributed to difference found. Castro et al. (34) and Braga et al. (39) also identified advanced age with decreased life quality scores in patients with chronic kidney disease.

Baseline emotional role score drew attention because of very low average value, even lower than those obtained by Santos (40), which evaluated correlation between depression and life quality of patients undergoing hemodialysis at Sobral (CE - Brazil); SF36 questionnaire was applied in a group of 166 patients; depressive patients showed lower scores of emotional role ( 25.6 vs. $62.5 ; \mathrm{p}=0.006)$, vitality $(40.7$ vs. 57.3; $\mathrm{p}=0.010)$ and mental health (50.1 vs. 65.4; $\mathrm{p}=0.023$ ). Regression analysis showed depression was predictive of emotional role and patients with depression presented a lower level of life quality.

On the other hand, it was in emotional role score we observed impact of rehabilitation program in a short interval of six weeks, unprecedented result considering that improvement of life quality was observed with at least eight weeks of interval between assessments. Painter et al. (41) and Oh-Park et al. (42), among other authors, observed increase in life quality through questionnaires, after conducting an exercise program. Using SF36 questionnaire, Painter et al. (41) verified effect of a program consisting of home exercises and aerobic training during hemodialysis in life quality of chronic kidney patients. After four months, these authors observed significant increment in following dimensions: physical functioning, role physical, bodily pain and general health.

Improvement in emotional role was possibly influenced by assistance and attention given to these patients, in addition to effect of time they spent together outside period of dialysis, and a time interval above six weeks would possibly lead to an improvement in other aspects of life quality, which has already been proven in other studies (15). Reboredo et al. (43) observed significant changes in physical and emotional aspects after 12 weeks of aerobic training and identified attention received by patients as a relevant factor to improve life quality of patients with chronic kidney disease.

Exercises and evaluations were a safe rehabilitation program and of easy application, but necessity of a follow-up by trained and competent professionals are important to highlight considering diversity of musculoskeletal and cardiovascular changes, as well as impact on functional capacity, which reinforces need for physiotherapist.

One aspect can be considered limitation of this study is a small sample size, which influences generalization of results; several patients discontinued treatment for different reasons. On the other hand, this research was carried out in a manner unprecedented with population from north region of Brazil, a location with its own characteristics, which are poorly explored in a scientific form. Even with limitations, results of this study were positive and fundamental to continuity of rehabilitation program for hemodialysis patients because this service did not exist prior 
to research. Considering this, there is the possibility of performing other future studies to raise level of scientific evidence on this subject.

Given positive results obtained in this study, it is justified collection of data with a larger sample of patients and for a extended period of time to increase even more the evidence of impact of physical therapy on functional capacity, clinical parameters, and above all, on life quality, since current trend of health care aims not only to contribute to life expectancy, but aims mainly to help individuals to live better.

\section{Conclusion}

Patients with chronic kidney disease undergoing dialysis treatment have physical and psychological changes that predispose to a sedentary lifestyle. In this population, routine prescription of physical exercise is not a common practice, especially in northern Brazil, in which there is a shortage of scientific research and health services. However, only six weeks of an exercise program contributed to improve functional capacity and emotional role of life quality, and it is expected to encourage an increasing number of research and publications, as well as rehabilitation services, in order to benefit this population.

\section{References}

1. Romão Júnior JE. Doença renal crônica: definição, epidemiologia e classificação. J Bras Nefrol. 2004; 26(3):1-3.

2. Sesso RCC, Lopes AA, Thomé FS, Lugon JR, Burdmann, EA. Brazilian dialysis census, 2009. J Bras Nefrol. 2010;32(4):380-4.

3. Peres LAB, Biela R, Herrmann M, Matsuo T, Ann HK, Camargo MTA, et al. Epidemiological study of end-stage kidney disease in western Paraná: an experience of 878 cases in 25 years. J Bras Nefrol. 2010; 32(1):51-6.

4. Bohannon RW, Smith J, Hull D, Palmeri D, Barnhard R. Deficits in lower extremity muscle and gait performance among transplant kidney candidates. Arch Phys Med Rehabil. 1995;76(6):547-51.
5. Sakkas GK, Sargeant AJ, Mercer TH, Ball D, Koufaki P, Karatzaferi C, et al. Changes in muscle morphology in dialysis patients after 6 months of aerobic exercise training. Nephrol Dial Transplant. 2003;18(9):1854-61.

6. Kosmadakis GC, Bevington A, Smith AC, Clapp EL, Viana JL, Bishop NC, et al. Physical exercise in patients with severe kidney disease. Nephron Clin Pract. 2010;115(1):c7-16.

7. Adams GR, Vaziri ND. Skeletal muscle dysfunction in chronic renal failure: effects of exercise. Am J Physiol Renal Physiol. 2006;290(4):F753-61.

8. Bohlke M, Nunes DL, Marini SS, Kitamura C, Andrade M, Von-Gysel MPO. Predictors of quality of life among patients on dialysis in southern Brazil. Sao Paulo Med J. 2008;126(5):252-6.

9. Hopman WM, Harrison MB, Coo H, Friedberg E, Buchanan M, VanDenKerkhof EG. Associations between chronic disease, age and physical and mental health status. Chronic Dis Can. 2009;29(2):108-16.

10. Carvalho T. Diretriz de reabilitação cardiopulmonar e metabólica: aspectos práticos e responsabilidades. Arq Bras Cardiol. 2006;86(1):74-82.

11. Martins MRI, Cesarino CB. Quality of life in chronic kidney failure patients receiving hemodialysis treatment. Rev Latino-am Enfermagem. 2005;13(5):670-6.

12. Reboredo MM, Henrique DMN, Bastos MG, Paula RB. Exercício físico em pacientes dialisados. Rev Bras Med Esporte. 2007;13(6):427-30.

13. Corrêa LB, Oliveira RN, Cantareli F, Cunha LS. Effect of peripheral muscle training on functional capacity and quality of life in patients on hemodialysis. J Bras Nefrol. 2009;31(1):18-24.

14. Tentori F. Focus on: physical exercise in hemodialysis patients. J Nephrol. 2008;21(6):808-12.

15. Segura-Ortí E. Ejercicio en pacientes en hemodiálisis: revisión sistemática de la literatura. Nefrologia. 2010; 30(2):236-46.

16. Nascimento LCA, Coutinho EB, Silva KNG. Effectiveness of physical exercise in chronic renal failure. Fisioter Mov. 2012;25(1):231-9.

17. ATS Committee on Proficiency Standards for Clinical Pulmonary Function Laboratories. ATS Statement: Guidelines for the Six-Minute Walk Test. Am J Respir Crit Care Med. 2002;166(1):111-7. 
18. Reboredo MM, Henrique DMN, Faria RS, Bergamini BC, Bastos MG, Paula RB. Correlation between the distance covered in the six-minute walk test with peak oxygen uptake in end-stage renal disease patients on hemodialysis. J Bras Nefrol. 2007;29(2):85-9.

19. Johansen KL, Painter P, Kent-Braun JA, Ng AV, Carey S, Silva M, et al. Validation of questionnaires to estimate physical activity and functioning in end-stage renal disease. Kidney Int. 2001;59(3):1121-7.

20. Arenas VG, Barros LFNM, Lemos FB, Martins MA, David-Neto E. Quality of Life: comparison between patients on automated peritoneal dialysis and patients on hemodialysis. Acta Paul Enfermagem. 2009;22(Special-Nephrology):535-9.

21. Najas CS, Pissulin FDM, Pacagnelli FL, Betonico GN, Almeida IC, Neder JA. Safety and accuracy of physical training in chronic renal insufficiency. Rev Bras Med Sport. 2009;15(5):384-8.

22. Nelson ME, Rejeski WJ, Blair SN, Duncan PW, Judge JO, King AC, et al. Physical activity and public health in older adults recommendation from the American College of Sports Medicine and the American Heart Association. Circulation. 2007;116(9):1094-105.

23. Portney LG, Watkins MP. Foundations of clinical research: applications to practice. 3rd ed. Upper Saddle River: Pearson/Prentice Hall; 2008.

24. Solway S, Brooks D, Lacasse Y, Thomas S. A qualitative systematic overview of the measurement properties of functional walk tests used in the cardiorespiratory domain. Chest. 2001;119(1):256-70.

25. Jatobá JPC, Amaro WF, Andrade APA, Cardoso FPF, Monteiro AMH, Oliveira MAM. Assessment of pulmonary function, respiratory muscular strength and six-minute walk test in chronic kidney disease patients on hemodialysis. J Bras Nefrol. 2008;30(4):280-7.

26. Cury JL, Brunetto AF, Aydos RD. Negative effects of chronic kidney failure on lung function and functional capacity. Rev Bras Fisioter. 2010;14(2):91-8.

27. Dipp T, Silva AMV, Signori LU, Strimban TM, Nicolodi G, Sbruzzi G, et al. Respiratory muscle strength and functional capacity in end-stage renal disease. Rev Bras Med Sport. 2010;16(4):246-9.
28. Painter P, Carlson L, Carey S, Paul SM, Myll J. Physical functioning and health related quality-of-life changes with exercise training in hemodialysis patients. Am J Kidney Dis. 2000;35(3):482-92.

29. Parsons TL, Toffelmire EB, King-Vanvlack CE. Exercise training during hemodialysis improves dialysis efficacy and physical performance. Arch Phys Med Rehabil. 2006;87(5):680-7.

30. Headley S, Germain M, Mailloux P, Mulhern J, Ashworth B, Burris J, et al. Resistance training improves strength and functional measures in patients with end stage renal disease. Am J Kidney Dis. 2002;40(2):355-64.

31. Henrique DMN, Reboredo MM, Chaoubah A, Paula RB. Aerobic exercise improves physical capacity of patients under chronic hemodialysis. Arq Bras Cardiol. 2010;94(6):823-8.

32. Kouidi E, Albani M, Natsis K, Megalopoulos A, Gigis P, Guiba-Tziampiri 0, et al. The effects of exercise training on muscle atrophy in haemodialysis patients. Nephrol Dial Transplant. 1998;13(3):685-99.

33. Valderrábano F, Jofre R, López-Gómez JM. Quality of life in end-stage renal disease patients. Am J Kidney Dis. 2001;38(3):443-64.

34. Castro M, Caiuby AVS, Draibe AS, Canziani MEF. Qualidade de vida de pacientes com insuficiência renal crônica em hemodiálise avaliada através do instrumento genérico SF-36. Rev Assoc Med Bras. 2003; 49(3):245-9.

35. Jonge P, Ruinemans GMF, Huyse FJ, Wee PM. A simple risk score predicts poor quality of life and non-survival at 1 year follow-up in dialysis patients. Nephrol Dial Transplant. 2003;18(12):2622-8.

36. Perlman RL, Finkelstein FO, Liu L, Roys E, Kiser M, Eisele G, et al. Quality of life in chronic kidney disease (CKD): the cross-sectional analysis in the Renal Research Institute - CKD study. Am J Kidney Dis. 2005; 45(4):658-66.

37. Silveira CB, Pantoja IKOR, Silva ARM, Azevedo RN, Sá NB, Turiel MGP, et al. Quality of life of hemodialysis patients in a Brazilian Public Hospital in Belém Pará. J Bras Nefrol. 2010;32(1):39-44.

38. Cavalcante MCV, Lamy ZC, Lamy Filho F, França AKTC, Santos AM, Thomaz EBAF, et al. Factors associated with the quality of life of adults subjected to hemodialysis in a city of northeast Brazil. J Bras Nefrol. 2013;35(2):79-86. 
39. Braga SF, Peixoto SV, Gomes IC, Acúrcio FA, Andrade EI, Cherchiglia ML. Factors associated with health-related quality of life in elderly patients on hemodialysis. Rev Saude Publica. 2011;45(6):1127-36.

40. Santos PR. Depression and quality of life of hemodialysis patients living in a poor region of Brazil. Rev Bras Psiquiatr. 2011;33(4):332-7.

41. Painter P, Carlson L, Carey S, Paul SM, Myll J. Low-functioning hemodialysis patients improve with exercise training. Am J Kidney Dis. 2000;36(3):600-8.

42. Oh-Park MO, Fast A, Gopal S, Lynn R, Frei G, Drenth R, et al. Exercise for the dialyzed: aerobic and strength training during hemodialysis. Am J Phys Med Rehabil. 2002;81(11):814-21.
43. Reboredo MM, Henrique DMN, Faria RS, Chaoubah A, Bastos MG, Paula RB. Exercise training during hemodialysis reduces blood pressure and increases physical functioning and quality of life. Artif Organs. 2010;34(7):586-93.

Received: 11/17/2013

Recebido: 17/11/2013

Approved: 06/30/2014

Aprovado: 30/06/2014 